\title{
Mohs Surgical Reconstruction Educational Activity: a resident education tool
}

\author{
Julie A Croley' \\ C Helen Malone' \\ Brandon P Goodwin' \\ Linda G Phillips ${ }^{2}$ \\ Eric L Cole ${ }^{2}$ \\ Richard F Wagner' \\ 'Department of Dermatology, \\ ${ }^{2}$ Division of Plastic Surgery, \\ Department of Surgery, The \\ University of Texas Medical Branch, \\ Galveston, TX, USA
}

This article was published in the following Dove Press journal:

Advances in Medical Education and Practice

8 February 2017

Number of times this article has been viewed

Correspondence: Julie A Croley Department of Dermatology, The University of Texas Medical Branch, 30I University Boulevard, Galveston, TX 77550, USA

Tel +l 4097727210

Email jaamthor@utmb.edu
Background: Surgical reconstructive planning following Mohs surgery can be a difficult subject for dermatology residents to master. Prior research demonstrates that active learning is preferred and more effective compared to passive learning models and that dermatology residents desire greater complexity and volume in surgical training. We present a novel, active, problem-based learning tool for the education of Mohs reconstruction with the goal of improving residents' ability to plan surgical reconstructions.

Materials and methods: The Mohs Surgical Reconstruction Educational Activity is an active, problem-based learning activity in which residents designed repairs for planned Mohs defects prior to surgery on an iPad application or on a printed photograph. The attending Mohs surgeon reviewed the reconstructive designs, provided feedback, guided discussion, and facilitated insight into additional issues requiring further review. Residents performed or observed the Mohs and reconstructive surgical procedures for respective repairs. Surveys were administered to participants before and after participating in the Mohs Surgical Reconstruction Educational Activity to assess the educational value of the activity. Survey responses were recorded on a 5-point Likert scale. Results: Mean participant-reported confidence in flap and graft knowledge, flap and graft planning, and flap and graft performance increased 1.50-2.50 Likert scale points upon completion of the Mohs surgery rotation by residents participating in the educational activity. The observed trend was larger in the dermatology resident subset, with increases of 2.00-3.50 Likert scale points reported for these questions. Mean participant-reported likelihoods of performing flaps and grafts in the future increased $0.25-0.50$ Likert scale points among all residents participating in the educational activity and $0.50-1.00$ Likert scale points in the dermatology resident subset. All residents participating in the educational activity somewhat or completely agreed with the statement, "I am faster at planning reconstructions after my Mohs rotation." In addition, $88 \%$ of participants "somewhat or completely agreed" that the exercise was a good educational experience.

Conclusion: The Mohs Surgical Reconstruction Educational Activity is a valuable novel tool for learning reconstructive planning that is easy to incorporate into existing dermatology residency curricula, inexpensive, and utilizes active learning.

Keywords: flaps, grafts, resident education, dermatologic surgery, Mohs surgery

\section{Introduction}

Mastery of planning and implementing surgical reconstructions following Mohs micrographic surgery can be a daunting task for residents and fellows. Many guiding principles but few strict absolutes and often several reasonable solutions for the same defect exist. One must take into account individual patient factors such as medical comorbidities 
and willingness to undergo multiple procedures to achieve a superior cosmetic result in reconstructive planning. Additional factors warranting consideration include local tissue mobility, respecting cosmetic subunits, preserving free margins, restoration of functionality, and camouflaging scars. Residents and fellows must learn to assimilate and apply the principles of reconstruction in addition to mastering a precise knowledge of local anatomy, soft tissue handling, and suturing techniques.

Active learning is preferred and more effective compared to passive learning models, yet a minority of dermatology residents engage in active learning processes in their surgical training. ${ }^{1-8}$ We present an active problem-based learning tool for the education of Mohs reconstruction that we have implemented as part of our institution's Mohs micrographic surgery rotation with the goal of improving residents' ability to plan surgical reconstructions.

\section{Materials and methods}

The Mohs Surgical Reconstruction Educational Activity, an active problem-based learning activity, was implemented as part of our institution's Mohs micrographic surgery rotation for the 2015-2016 academic year. The activity protocol is as follows: 1) Residents chose two patients scheduled for Mohs surgery per week. Tumor locations for the two weekly patients must have belonged to different cosmetic subunits. 2) Residents obtained preoperative photographs from the shared department drive by either uploading them to the YouDoodle iPad application or printing a paper copy. 3) Residents drew repairs directly on preoperative photographs either electronically using the YouDoodle iPad application (Figure 1) as described by DuPont et $\mathrm{al}^{9}$ or on the printed photograph. The planned firststage excision was drawn and the size recorded. Two surgical repairs were designed for each of the weekly patients. The two repairs were next ranked in order of preference. 4) On the day of surgery, the attending Mohs surgeon reviewed the reconstructive designs, provided expert feedback, and guided discussion, including possible alternate reconstructions and individual patient considerations. Learning objectives were also emphasized. 5) Residents assisted with the Mohs and reconstructive surgical procedures for the two respective patients (Figure 2).

Voluntary surveys were distributed to dermatology $(n=4)$ and plastic surgery residents $(n=4)$ before and after the Mohs micrographic surgery rotation. Prerotation questions evaluated experience in flap and graft performance and observation. Survey questions further evaluated resident confidence in planning and performing flaps and grafts before and after the Mohs surgery rotation, as well as flap and graft repair knowledge before and after the rotation. Questions also evalu-
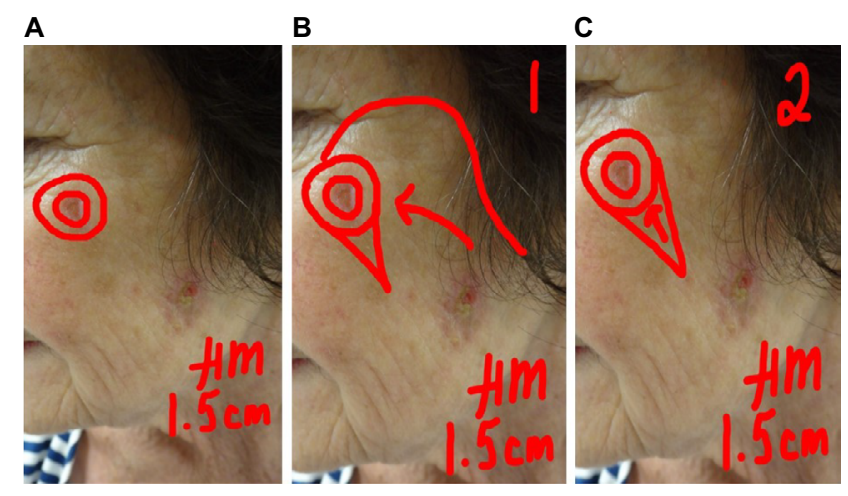

Figure I Preoperative reconstructive planning using the YouDoodle iPad application.

Notes: (A) The planned first-stage excision is drawn and the size recorded. (B) One reconstructive option is proposed. (C) A second reconstructive option is proposed. Repairs are ranked for preference.

ated the likelihood of using these reconstructive modalities in the future, the degree to which learning objectives were met during the Mohs rotation, and the speed in planning reconstructions following the rotation. Answers were recorded on a 5-point Likert scale. Mean differences were calculated between pre- and postrotation surveys.

The study was exempt from review by the Institutional Review Board at the University of Texas Medical Branch in accordance with the US Department of Health and Human Services Office for Human Research Protections Code of Federal Regulations, title 45 part $46.101 \mathrm{~b}$ and fits into categories 1 (education research) and 2 (survey study) of the federally designated exempt review categories. Consent was obtained for patient photographs used in the educational activity, which represents no change from previous practice.

\section{Results}

Mean participant-reported confidence in flap and graft knowledge, flap and graft planning, and flap and graft performance increased 1.50-2.50 Likert scale points upon completion of the Mohs surgery rotation by residents participating in the educational activity. The observed trend was larger in the dermatology resident subset, with increases of 2.00-3.50 Likert scale points reported for these questions. Mean participant-reported likelihoods of performing flaps and grafts in the future increased $0.25-0.50$ Likert scale points among all residents participating in the educational activity and 0.50-1.00 Likert scale points in the dermatology resident subset (Table 1). All residents participating in the educational activity somewhat or completely agreed with the statement, "I am faster at planning reconstructions after my Mohs rotation" (mean Likert score of 4.75 out of 5.00). All residents somewhat or completely agreed that the following learning 


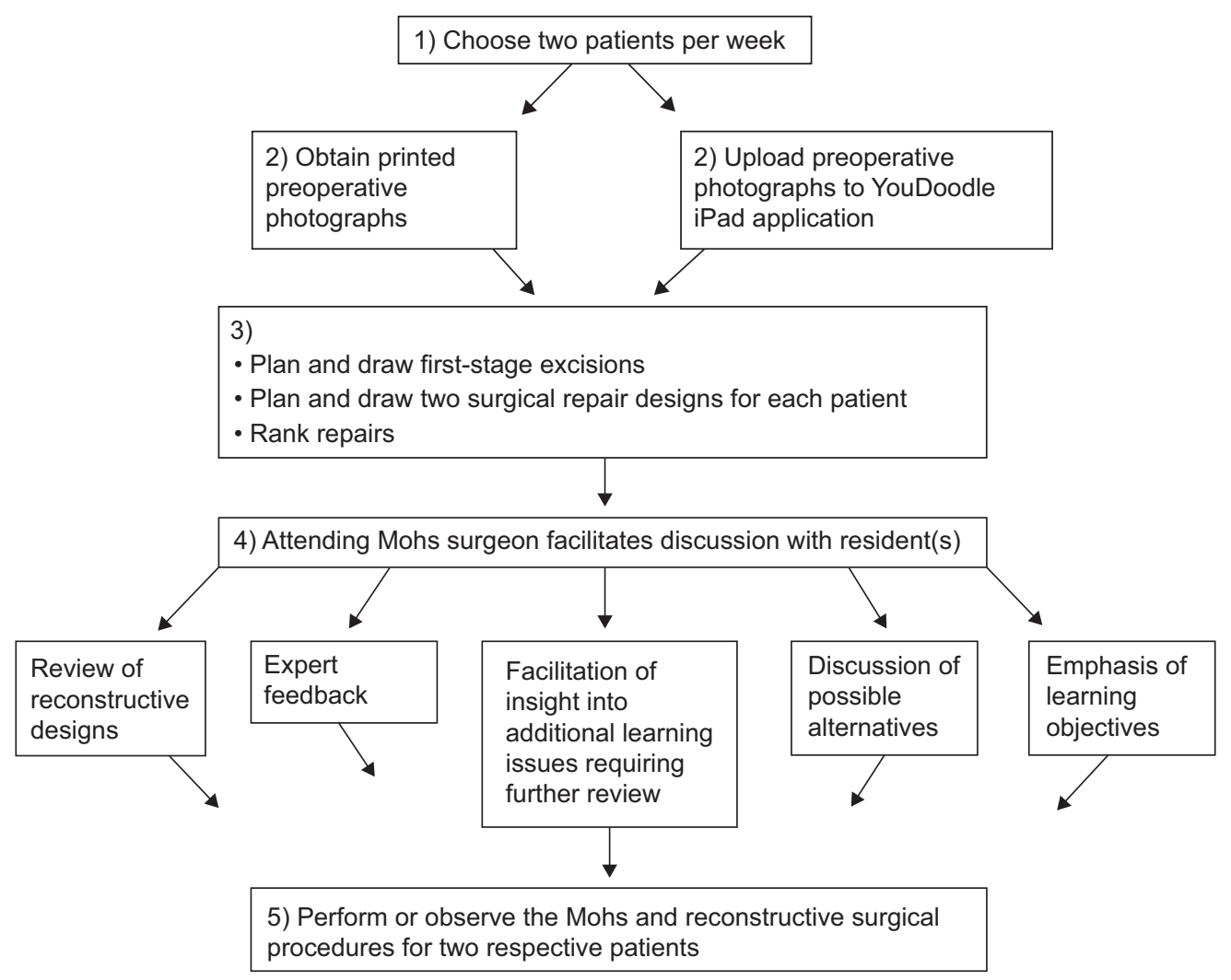

Figure 2 Mohs Surgical Reconstruction Educational Activity protocol.

Table I Mean differences between pre- and post-Mohs surgery rotation survey responses (postrotation survey response minus prerotation survey response) on 5-point Likert scale

\begin{tabular}{|c|c|c|}
\hline Survey question & $\begin{array}{l}\text { Mean difference } \\
\text { between pre- } \\
\text { and post-Mohs } \\
\text { surgery rotation } \\
\text { survey responses: } \\
\text { dermatology and } \\
\text { plastic surgery } \\
\text { residents }\end{array}$ & $\begin{array}{l}\text { Mean difference } \\
\text { between pre- } \\
\text { and post-Mohs } \\
\text { surgery rotation } \\
\text { survey responses: } \\
\text { dermatology } \\
\text { residents only }\end{array}$ \\
\hline $\begin{array}{l}\text { Likelihood of using } \\
\text { flap in the future }\end{array}$ & +0.25 & +0.50 \\
\hline $\begin{array}{l}\text { Likelihood of using } \\
\text { graft in the future }\end{array}$ & +0.50 & +1.00 \\
\hline $\begin{array}{l}\text { Confidence in flap } \\
\text { knowledge }\end{array}$ & +1.63 & +2.00 \\
\hline $\begin{array}{l}\text { Confidence in graft } \\
\text { knowledge }\end{array}$ & +1.50 & +2.25 \\
\hline $\begin{array}{l}\text { Confidence in flap } \\
\text { planning }\end{array}$ & +1.88 & +2.50 \\
\hline $\begin{array}{l}\text { Confidence in graft } \\
\text { planning }\end{array}$ & +1.75 & +2.75 \\
\hline $\begin{array}{l}\text { Confidence in flap } \\
\text { performance }\end{array}$ & +2.50 & +3.25 \\
\hline $\begin{array}{l}\text { Confidence in graft } \\
\text { performance }\end{array}$ & +2.00 & +3.50 \\
\hline
\end{tabular}

objectives were met by the educational activity: identify and know the four main types of flaps, understand how each of the four main types of flaps move, understand how/when flaps may be used in dermatologic surgery, identify and know the main types of grafts, and understand how/when grafts may be used in dermatologic surgery (mean Likert scores 4.50-5.00). Additionally, $88 \%$ of participants "somewhat or completely agreed" that the exercise was a good educational experience. The only resident who did not find the study useful also spent the least amount of time per patient preparing for the educational activity ( $<15$ minutes per patient). Survey comments were generally positive and included the following: "This was a fantastic experience, and I learned a great deal from [the faculty facilitator]. I feel more confident in designing flaps and grafts." "Teaching style was great and allowed us to actively participate in planning for surgery." Only one resident used the YouDoodle iPad application for designing repairs. The others designed repairs on a printed photograph.

\section{Discussion}

Classic training in surgical reconstruction following Mohs surgery relies primarily on passive learning processes, 
most frequently in the form of independent study, didactic lectures, and observance of the procedure alongside the surgeon. However, it has been shown by Stratman et $\mathrm{al}^{1}$ that dermatology residents prefer active learning, most frequently in the form of hands-on direct learning, addressing patient problems, and teaching others. Problem-based learning, one form of active learning, has been shown to improve recall of knowledge used to solve problems and ability to solve future similar problems. ${ }^{2}$ In this model, the teacher presents a dermatology case, guides discussion, and facilitates insight into additional issues requiring further review. Goodwin and Wagner ${ }^{3}$ described a surgical workshop as another model of active learning, in which surgical repairs were planned on photographs of Mohs defects and actual and possible repairs were discussed. The workshop was shown to significantly improve resident confidence in performing flaps. An active learning model in the form of direct hands-on peer-assisted learning of procedural dermatology in a workshop setting has also been described by Duran-Nelson et al. ${ }^{4}$ Learner self-reported knowledge increased from 3 to 9.5 on a scale of 1-10 at the workshop's conclusion. In all, $96 \%$ of participants rated the experience as being of educational value.

While active learning processes have been shown to be preferred and more effective than passive learning models, a surprisingly low proportion of residents engage in active learning processes when learning surgical dermatology. A survey to 240 dermatology program directors, surgical training directors, and senior residents reveals that only $17.5 \%$ of residents take stages for Mohs surgery in the majority of cases and $49.2 \%$ act as the primary surgeon for reconstruction. ${ }^{5}$ A separate survey conducted by Todd et $\mathrm{al}^{6}$ reveals that only $51 \%$ of the 112 participating residency programs give residents the opportunity to act as the primary surgeon during Mohs cases, with $22 \%$ of programs reporting that residents operate as the primary Mohs surgeon in fewer than 10 cases during their residency.

Prior research demonstrates that surgical training during residency is important to dermatology residents, especially complex surgical skills. ${ }^{7}$ In one study by Reichel et al, chief residents rated complex surgical procedures, such as fullthickness skin grafts, local flaps, and facial nerve blocks, as essential skills to learn more often than their faculty counterparts. In addition to learning complex dermatologic surgical procedures, residents desire a greater quantity of training in surgical dermatology. A survey study of 180 recent dermatology residency graduates demonstrates a preference for greater time allocation to surgical and cosmetic training in residency curriculums than is currently practiced. ${ }^{8}$ Resident preferences for higher volume and complexity of dermatologic surgery coincide with a rapid change in the clinical practice of dermatology during the past two decades toward an expansion in the variety and complexity of surgical procedures offered. ${ }^{10}$ The Mohs Surgical Reconstruction Educational Activity provides an active problem-based learning approach to resident education of surgical reconstructive planning following Mohs micrographic surgery. Although our study of eight participants was underpowered to conduct statistical analyses, residents generally expressed that the activity was a valuable learning experience in the survey comments section. Furthermore, residents participating in the educational activity rated their postrotation confidence in planning flaps and grafts, performing flaps and grafts, and knowledge of flaps and grafts higher than prerotation responses. All residents participating in the educational activity somewhat or completely agreed that speed of planning reconstructions improved after participating in the activity. Our findings are consistent with prior research that active, problem-based learning methods are effective in the surgical education of dermatology residents. ${ }^{1-4}$

Limitations of our study include small number of participants $(n=8)$. Furthermore, a marked preference for designing repairs on the printed photograph over the YouDoodle iPad application was observed. We hypothesize that the cumbersome process of uploading preoperative photographs from the department drive to the iPad application posed a barrier to use of this option. In the future, streamlining the process of uploading preoperative photographs may encourage increased use of the YouDoodle application option.

\section{Conclusion}

Surgical reconstructive planning following Mohs surgery can be a difficult subject for dermatology residents to master. Incorporation of active teaching tools may be a beneficial addition to surgical curricula. The Mohs Surgical Reconstruction Educational Activity is a valuable novel teaching tool for learning reconstructive planning that is easy to incorporate into existing dermatologic surgical curricula, inexpensive, and utilizes active learning.

\section{Acknowledgments}

Oral Presentation at the American Academy of Dermatology Annual Meeting, Dermatology Teachers Exchange Group Session, Washington, DC, USA, March 4, 2016. 


\section{Disclosure}

The authors report no conflicts of interest in this work.

\section{References}

1. Stratman E, Vogel C, Reck C, Mukesh B. Analysis of dermatology resident self-reported successful learning styles and implications for core competency curriculum development. Med Teach. 2008;30(4):420-425.

2. Stratman E, Dyer J. Problem-based learning: an approach to dermatology resident education. Arch Dermatol. 2002;138(10):1299-1301.

3. Goodwin B, Wagner R. Surgical flap and graft reconstruction workshop for dermatology residents. J Cosmet Dermatol Sci Appl. 2015;5(2):86-93.

4. Duran-Nelson A, Baum K, Weber-Main A, Menk J. Efficacy of peerassisted learning across residencies for procedural training in dermatology. J Grad Med Educ. 2011;3(3):391-394.
5. Lee E, Nehal K, Dusza S, Hale E, Levine V. Procedural dermatology training during dermatology residency: a survey of third-year dermatology residents. J Am Acad Dermatol. 2011;64(3):475-483.

6. Todd M, Miller J, Ammirati C. Dermatologic surgery training in residency. Dermatol Surg. 2009;28(7):547-550.

7. Reichel J, Perison R, Berg D. Teaching and evaluation of surgical skills in dermatology. Arch Dermatol. 2004;140(11):1365-1369.

8. Reid D, Kimball A, Ehrlich A. Letter: medical versus surgical dermatology: how much training do residents receive? Dermatol Surg. 2006; 32(4):597.

9. DuPont J, Whitaker D, Zeitouni N. Drawing app in Mohs fellowship training: a useful tool in learning surgical reconstruction. Clinical Pearls Abstract Session at the 47th Annual Meeting of the American College of Mohs Surgery; May 2, 2015; San Antonio, TX.

10. Callen J. Dermatologic surgery training during residency: room for improvement. Dermatol Surg. 2011;27(5):508-510.
Advances in Medical Education and Practice

\section{Publish your work in this journal}

Advances in Medical Education and Practice is an international, peerreviewed, open access journal that aims to present and publish research on Medical Education covering medical, dental, nursing and allied health care professional education. The journal covers undergraduate education, postgraduate training and continuing medical education

\section{Dovepress}

including emerging trends and innovative models linking education, research, and health care services. The manuscript management system is completely online and includes a very quick and fair peer-review system. Visit http://www.dovepress.com/testimonials.php to read real quotes from published authors.

Submit your manuscript here: http://www.dovepress.com/advances-in-medical-education-and-practice-journal 